\title{
THE EFFECT OF VENTILATION AND ECONOMIZER ON ENERGY CONSUMPTIONS FOR AIR SOURCEHEAT PUMPS IN SCHOOLS
}

\author{
Nihal Al Raees, Nabil Nassif and Fouad Al Rifaie \\ Department of Civil, Architectural and Environmental Engineering, \\ North Carolina A and T State University, NC 27411, Greensboro, USA
}

Received 2014-01-30; Revised 2014-02-22; Accepted 2014-03-18

\begin{abstract}
The study discusses the applications of $\mathrm{CO}_{2}$-based demand-controlled ventilation DCV strategy integrated with the economizer for air source heat pumps in schools, investigates their impact on the annual heating, cooling and total energy consumption, also determines the potential savings achieved in different USA locations. The study includes detailed energy analysis on an existing middle school through whole building simulation energy software. The simulation model is first calibrated and checked for accuracy using actual monthly utility data. This model is then used for savings calculations resulted from a combination of air-side economizer and $\mathrm{CO}_{2}$-based $\mathrm{DCV}$ and with various occupancy profiles and locations. The results show that a significant saving could be obtained as compared to the actual operating strategy implemented in the existing system and this saving depends mainly on the actual occupancy profile and building locations.
\end{abstract}

Key words: HVAC Systems, Ventilation Control, Heat Pump, $\mathrm{CO}_{2}$ Concentration, Economizer

\section{INTRODUCTION}

Ventilating the building with a fresh air to maintain a proper Indoor Air Quality (IAQ) is one of the major loads added to the HVAC system (Chao and $\mathrm{Hu}, 2004$; Shan et al., 2012). School buildings have much more concerns about IAQ due to the fact that children spend $12 \%$ of their life time in classrooms (Santamouris et al., 2008). Controlling ventilation is recommended to maintain the minimum airflow rate that is specified by ASHRAE (2010) and avoid over ventilation and thereby reduce energy consumption in buildings (Wang and $\mathrm{Xu}$, 2002; Nassif, 2012; Shan et al., 2012). Many ventilation control strategies are proposed for HVAC system (Nassif et al., 2005; Lu et al., 2011; Mysen et al., 2007; Ng et al., 2011). $\mathrm{CO}_{2}$-based Demand Control Ventilation $\left(\mathrm{CO}_{2}-\mathrm{DCV}\right)$ is one of the strategies that could lower energy use by reducing over ventilation of buildings (Nassif, 2012; Taylor, 2006; Stanke, 2006). Most DCV strategies are based on flow rate per person, which may not necessary comply with the new ventilation requirements of ASHRAE (2010). As the new standard requires two ventilation rates, one intended to dilute the contaminants generated by occupants and other for building-related sources, the required space $\mathrm{CO}_{2}$ concentration or the indoor-outdoor difference is no longer constant, making any $\mathrm{CO}_{2}$-based DCV strategy hard to apply (Stanke 2006; Murphy, 2005; Nassif, 2012). In this study, two control methods (1) proportional control and (2) single set point control are presented for the $\mathrm{CO}_{2}$ control. The study also discusses the applications of $\mathrm{CO}_{2}$-based demand-controlled ventilation DCV strategy integrated with the economizer operating strategy for air source heat pumps in schools,

Corresponding Author: Nabil Nassif, Department of Civil, Architectural and Environmental Engineering,

North Carolina A and T State University 455 McNair Hall 1601 E. Market Street Greensboro,

USA Tel: (336) 285-3680 Fax: (336) 334-7126 
investigates their impact on the annual energy consumption and determines the potential savings achieved in different USA locations. The methodology used in this study includes (1) modeling an existing middle school building located in North Carolina, equipped with a total of forty nine wall mounted air source heat pumps, using the whole building simulation energy software eQuest, (2) comparing the energy consumption simulated by the model with the actual monthly energy data collected over five years for model calibration and testing for the accuracy and (3) running the validated model with $\mathrm{CO}_{2}$-based demand-controlled ventilation DCV and economizer for different occupancy profiles and USA ASHRAE climate zones to estimate the energy savings as compared to the actual operating strategy applied in the investigated system.

\section{2. $\mathrm{CO}_{2}$-BASED DEMAND CONTROLLED VENTILATION AND ECONOMIZER}

A middle school building with a 133,200 ft2 located in US is used for this study. There are two types of HVAC system the first is single zone system with a total of forty nine wall mounted air source heat pumps located in classrooms. The capacities of heat pumps vary from 2 to 4 tons, with airflow rates ranging from 800 to $1400 \mathrm{cfm}$. There are 27 directexpansion DX coil units supplying conditioned air to offices, gyms and other general areas. The airflow rates of those units range from 600 and $8000 \mathrm{cfm}$. A fixed amount of fresh is supplied to the space based on design number of students. There is no economizer applied in this system. Thus, this study will investigate the energy benefits of using the $\mathrm{CO}_{2}$-based DCV integrated with economizer operation, which can be done by installing modulated damper, $\mathrm{CO}_{2}$ sensor and controller as shown in Fig. 1.

The temperature or enthalpy control strategy could be applied for economizer operation. In this case, the outdoor air temperature and/or relative humidity readings should be also available for the controller. The $\mathrm{CO}_{2}$ sensor can be installed on the wall in the class room, just like the thermostat. The controller will use the $\mathrm{CO}_{2}$ signal to control and modulate the position of outdoor air damper and thereby provide the space with the proper amount of ventilation air. Two possible $\mathrm{CO}_{2}$ control approaches could be used (a) proportional control based on the calculations in Appendix A of the ASHRAE 62.1-2010 user's manual
(ASHRAE Standard 62.1 2010) or (b) single set point control as described by Murphy (2005). Those control approaches are discussed below.

The ASHRAE Standard 62.1-2010 prescribes two ventilation rates, one intended to dilute the contaminants generated by occupants ( $\mathrm{Rp}$ ) and other for buildingrelated sources $(\mathrm{Ra})$.

For a single zone, the required minimum outdoor air rate $\mathrm{Voz}$ as a function of the number of zone occupants $\mathrm{Pz}$ and the zone floor area $\mathrm{Az}$ is given:

$\mathrm{V}_{\mathrm{oz}}=\frac{\mathrm{R}_{\mathrm{p}} \times \mathrm{P}_{\mathrm{z}}+\mathrm{R}_{\mathrm{a}} \times \mathrm{A}_{\mathrm{z}}}{\mathrm{E}_{\mathrm{z}}}$

The $\mathrm{Rp}$ and $\mathrm{Ra}$ are determined from the table in standard 62.1 based on the occupancy type. The zone outdoor air rate needs to be adjusted to account for the supply diffuser and return grill location, supply air temperature and other factors by including the space air distribution Effectiveness Ez.

ASHRAE Standard 62.1 provides the mass balance equation to predict the difference between indoor $\mathrm{CO}_{2}$ Concentration $(\mathrm{Cz})$ and outdoor $\mathrm{CO}_{2}$ concentration (Co) at steady-state conditions (the air supplied to the space is assumed to be well mixed and the efficiency:

$\mathrm{V}_{\mathrm{oz}}=\frac{\mathrm{N}_{\mathrm{z}}}{\left(\mathrm{C}_{\mathrm{z}}-\mathrm{C}_{\mathrm{o}}\right)}$

The $\mathrm{Nz}$ is the $\mathrm{CO}_{2}$ generation rate and it is a function of people number $(\mathrm{Nz}=\mathrm{C} \times \mathrm{Pz})$; where the $\mathrm{C}$ is a constant value related to the occupancy activities, level, diet, health and etc. The space $\mathrm{CO}_{2}$ concentration $\mathrm{Cz}$ is given (using Equation 2 and $1, \mathrm{Ez}=1$ ):

$\mathrm{C}_{\mathrm{z}}=\mathrm{C}_{\mathrm{o}}+\frac{\mathrm{N}_{\mathrm{z}}}{\mathrm{V}_{\mathrm{oz}}}=\mathrm{C}_{\mathrm{o}}+\frac{\mathrm{C} \times \mathrm{P}_{\mathrm{z}}}{\mathrm{R}_{\mathrm{p}} \times \mathrm{P}_{\mathrm{z}}+\mathrm{R}_{\mathrm{a}} \times \mathrm{A}_{\mathrm{z}}}$

As indicated in Equation 1, because of those two different ventilation rates, the required space $\mathrm{CO}_{2}$ concentration is no longer constant as it was in ASHRAE Standard 62.12001 and making any $\mathrm{CO}_{2}$ based DCV strategy hard to apply and comply exactly with the recommendations of the Standard 62.1 2010. Thus, two control approaches "proportional control" and "single set point control" are presented for the single zone $\mathrm{CO}_{2}$ control. 


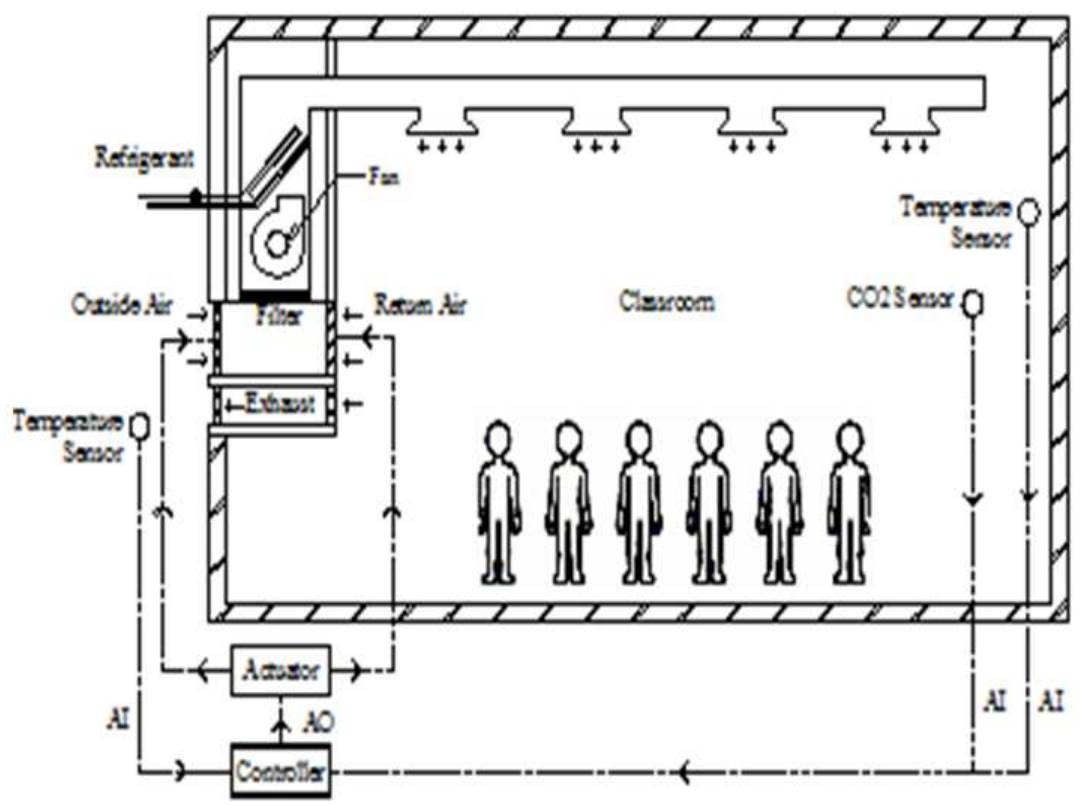

Fig. 1. Schematic of air source heat pump located in the classroom when integrate DCV and economizer.

In the proportional control, the outdoor airflow rate supplied to the space (Voz-supply) is determined by the following proportional control Equation 4:

$$
\mathrm{V}_{\mathrm{oz}-\text { sup ply }}=\frac{\mathrm{C}_{\mathrm{z}-\text { actual }}-\mathrm{C}_{\mathrm{z}-\text { min }}}{\mathrm{C}_{\mathrm{z} \text {-design }}-\mathrm{C}_{\mathrm{z}-\text { min }}}\left(\mathrm{V}_{\mathrm{oz}-\text { design }}-\mathrm{V}_{\mathrm{oz}-\text { min }}\right)+\mathrm{V}_{\mathrm{oz}-\text { min }}
$$

The required $\mathrm{CO}_{2}$ concentrations at the design full occupancy (Cz-design) and at the minimum occupancy (Cz-min) and the required fresh air based on the design population Voz-design and on the minimum occupancy Voz-min are determined as the following:

- The required $\mathrm{CO}_{2}$ concentration at the design occupancy Cz-design is determined by Equation 3 and using $\mathrm{Pz}$ at design occupants (Pz-design).

- The required $\mathrm{CO}_{2}$ concentration at the minimum occupancy $\mathrm{Cz}$-min is determined by the same equation but by using Pz-min, e.g., 40\% of design occupants (adjustable)

- The required fresh air based on the design zone population Voz-design is determined by Equation 1 and using $\mathrm{Pz}$ at the design occupancy (Pz-design)

- The required fresh air based on the minimum occupancy Voz-min is determined by Equation 1 and by using minimum Pz-min (40\% of design occupant)

- The control adjusts the outdoor airflow rate Vozsupply supplied to the space proportionally between Voz-min and Voz-design when the actual space $\mathrm{CO}_{2}$ concentration $\mathrm{Cz}$-actual (measured) is between $\mathrm{Cs}$-min and $\mathrm{Cs}$-design

This proportional control strategy is easy to implement and yields an outdoor air flow supplied to the space (Voz-supply) that equals or exceeds the requirements (Voz) (Murphy, 2005) but it needs two limits and outdoor airflow measurement.

In a single set point control, the modulated outdoor damper is controlled to maintain the $\mathrm{CO}_{2}$ concentration $\mathrm{Cz}$-setpoint at a value calculated by Equation 2 and based on the required fresh air at the minimum occupancy (Voz-min) as a follow.

As described by Murphy (2005), the single set point approach results in outdoor airflow provided to the space that equals or exceeds the ventilation rate required by ASHRAE 62.1. The strategy is simple to implement and it requires a modulating outdoor air damper and the controller needs only one outdoor air damper set point (Voz-min) and one $\mathrm{CO}_{2}$ set point (Cs-min) rather than two limits and outdoor air flow measurement.

\section{MODELLING}

An energy simulation software eQuest is used for the energy performance analysis. The detailed information on building and system was entered into the software and then the model outputs are compared with the actual data from utility bills of five years. The model was first 
calibrated using the data of year 2009 and then tested for other four years $(2007,2008,2010$ and 2011). Figure 2 shows the comparison between the simulated and utility data for 2009. A calibration process began in order to reduce the error between the actual data and model outputs. Detailed information on schedule, equipment, lighting, etc. was collected and readjusted. The main adjustment was related to various occupant and equipment schedules due to different days and seasons. As example, different schedules are considered for summer, winter, holiday, weekday, weekend and so on. Our stopping criteria are to obtain an error of $5 \%$ or less. The error resulted by comparing annual consumption between the model and utility data is $0.6 \%$. However, as shown in Fig. 2 , by comparing the energy consumption per season, the errors are still within the $5 \%$, for instance, $1.2 \%$ in winter, $4 \%$ in spring, $2.4 \%$ in summer and $3.5 \%$ in fall.

After the model was calibrated using the utility data of 2009 , the model is then tested for other four years (2007, 2008, 2010 and 2011). Figure 3 shows comparison between the simulated and utility data for five years. The model errors are $2.3 \%$ for $2007,8.2 \%$ for 2008, $0.6 \%$ for 2009 (calibrated period), 9\% for 2010 and $6.5 \%$ for 2011 . Thus, the model uses in next section for energy saving calculations.

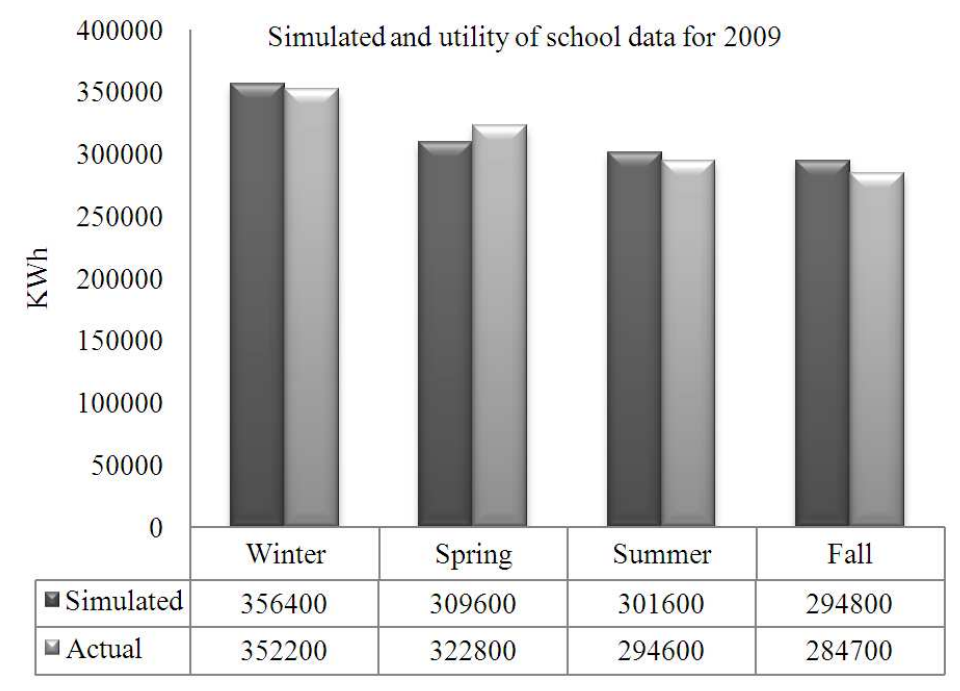

Fig. 2. Comparison between the simulated and utility data for 2009

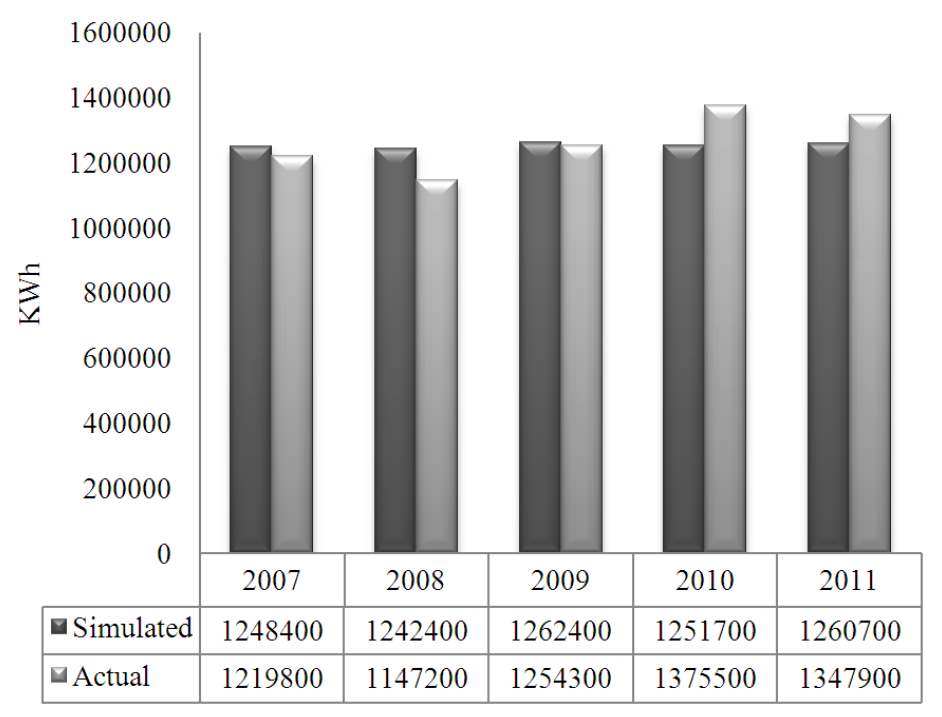

Fig. 3. Comparison between the simulated and utility data for five years 


\section{RASULTS AND DISCUSSION}

The calibrated model developed by eQuest and discussed before is used for estimating the energy savings that could be resulted by implementing the $\mathrm{CO}_{2}$-based DCV along with the economizer on heat pumps located in the classrooms and the offices. As they are currently installed in the investigated school, the outdoor air intake provides a fixed amount of fresh air based on design number of students. Even if the outside air is suitable for free cooling, the system always provides this amount of air as there is no modulated damper and associated control installed. To demonstrate the energy saving from implementing the $\mathrm{DCV}$, it is assumed that the occupancy profile varies from $100 \%$ as low as $50 \%$. The enthalpy control for economizer is used in this study. Figure 4 shows the annual cooling, heating and total energy consumptions when both DCV and economizer are implemented with different occupancy profiles $(100,90,80,70,60$ and $50 \%$ of design occupancy profile). The simulation is done for Greensboro, NC. The fan power is not included in the cooling and heating energy consumption as shown in Fig. 4 but the fan power is included in the total energy consumption. The baseline represents the case when the economizer and DCV are not implemented. When the occupancy is always at design condition as indicated by $100 \%$, the saving resulted is only due to the economizer operation and there is no saving obtained from DCV. In this case, the total energy consumption drops from $1,258,300$ to $1,170,600 \mathrm{kWh}$, a saving of about $7 \%$ due to the economizer operation only. However, when the occupancy is less than design condition for example, 90, 80, 70, 60 and 50\%, the savings result due to both economizer and DCV. When the DCV and the economizer are integrated into the heat pump design, both energy cooling and heating consumptions drop significantly. As example, when the actual occupancy is $50 \%$ less than design one, the energy use drops from 315,700 to $217340 \mathrm{kWh}$ for cooling, from 118,900 to $65,590 \mathrm{kWh}$ for heating and from $1,258,300$ to $965,720 \mathrm{kWh}$ for total annual building energy use.

The simulations are repeated for various USA locations covering most ASHRAE climate zones. Figure 5 shows the energy consumption and Fig. 6 shows energy saving obtained by implementing the DCV and economizer in various USA locations. However, Table 1 shows the percentage of the annual energy saving resulted first from DCV only and second from both Economizer (ECO) and DCV combined. Again, the baseline represents the case when the economizer and DCV are not implemented. As shown in Fig. 5 and 6, if the actual occupancy is 50\% less than design value, the energy consumption drops of about $304,600 \mathrm{kWh}$, with saving of $23 \%$ in Las Vegas, for instance. While in Miami the drop is about 255,800 $\mathrm{kWh}$ and the saving is $15 \%$ of total energy use.

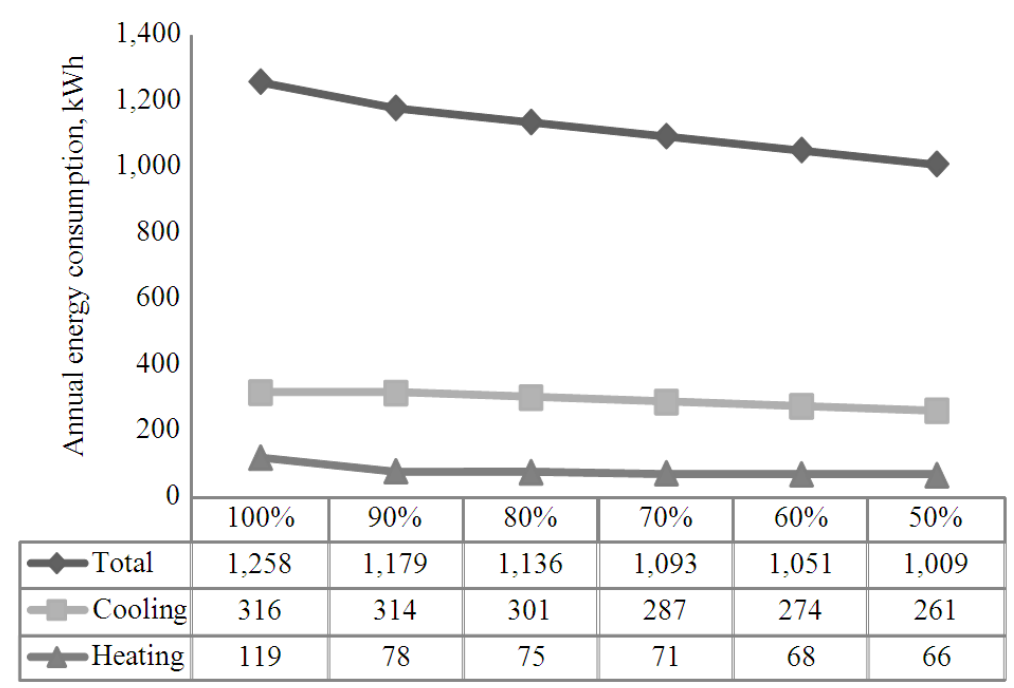

Fig. 4. Annual cooling, heating and total energy consumptions when both DCV and economizer are implemented with different occupancy profiles (Greensboro, NC) 


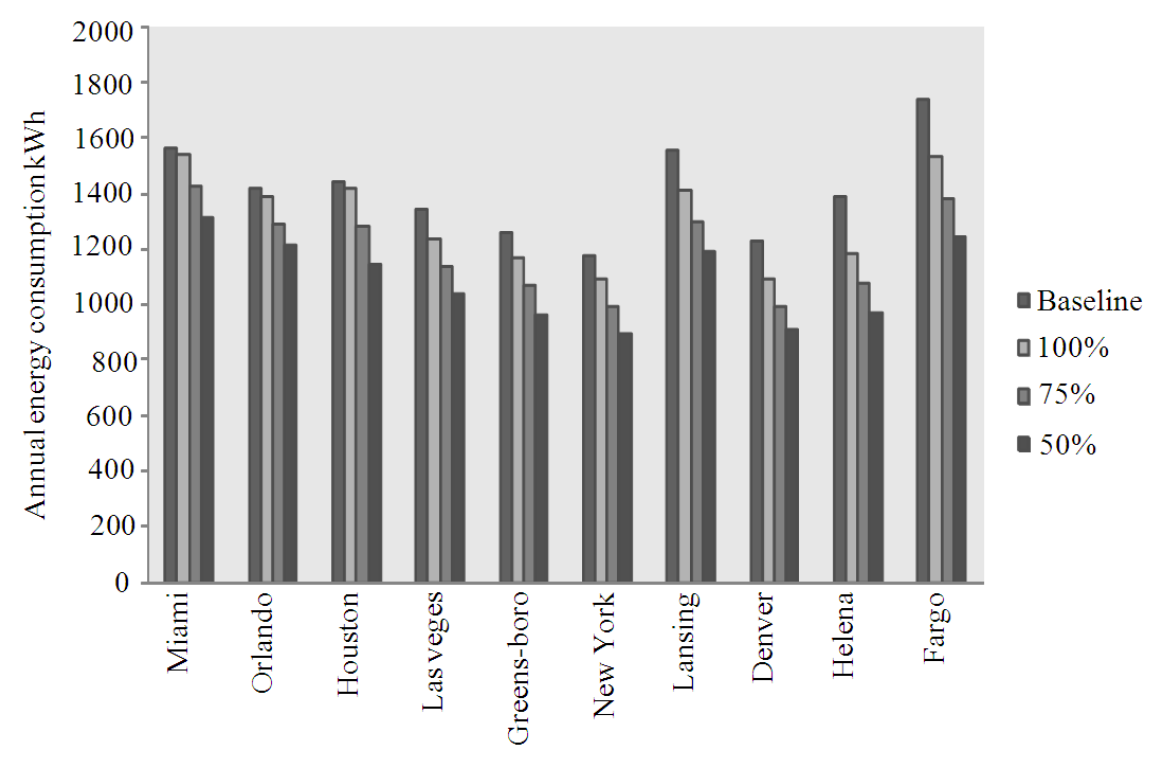

Fig. 5. Energy consumption due to the DCV along with economizer in various locations

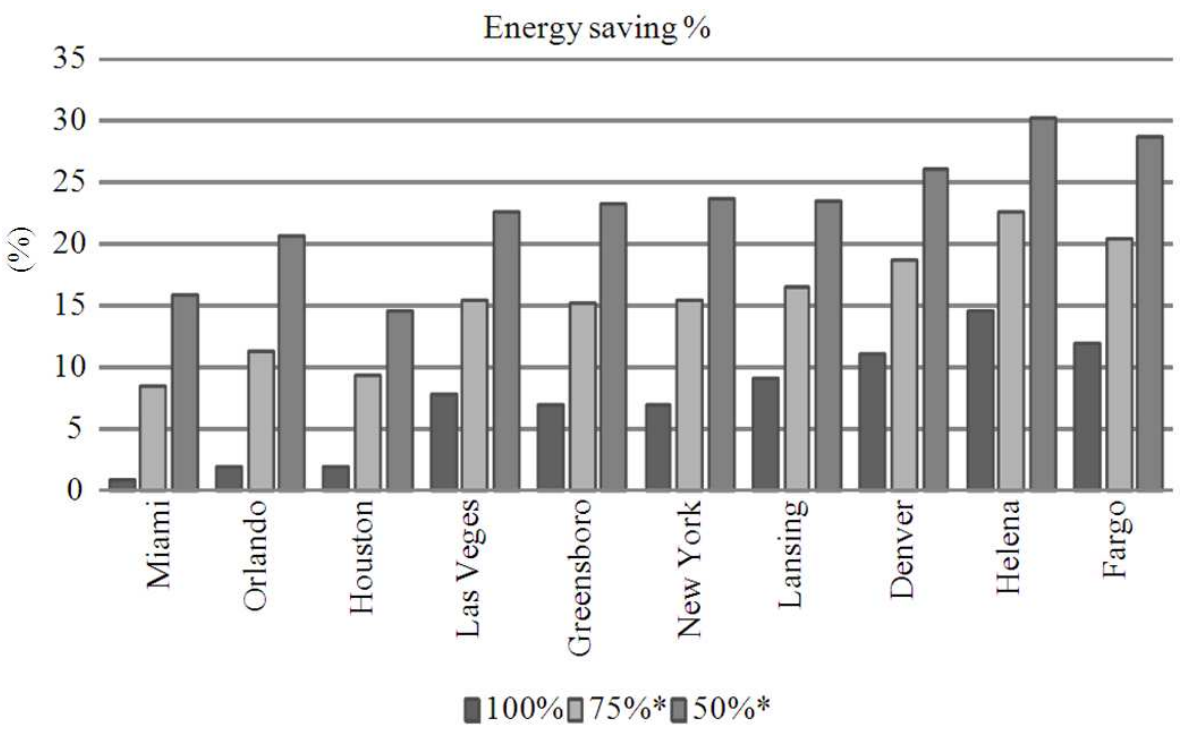

Fig. 6. Energy saving percentage due to the DCV along with economizer in various locations

The energy saving due to the economizer varies with location's climate weather and the energy saving due to the DCV varies with locations and actual occupancy changes.

As indicated in Table 1, when the occupancy is always at $100 \%$ there is no saving associated with DCV and the saving is resulted only from the economizer and it is clear that saving from the economizer operation is higher in Las Vegas (Climate Zone 5B and dry) than
Orlando (Climate Zone 2 A, Hot-Humid ). A substantial energy saving is resulted by implementing the DCV. The saving increases as the actual occupancy becomes less than design value. If the actual occupancy becomes $50 \%$ of design value, the saving is $19 \%$ for Orlando and this saving amount varies with the locations. However, in Table 2, the percentage of saving in energy use for the annual cooling heating and total resulted from both DCV and economizer. 
Nihal Al Raees et al. / American Journal of Engineering and Applied Sciences 7 (1): 58-65, 2014

Table 1. Percentage of the annual energy saving resulted from first the DCV only and second from both Economizer (ECO) and DCV combined

\begin{tabular}{|c|c|c|c|c|}
\hline & \multicolumn{2}{|l|}{ Orlando } & \multicolumn{2}{|c|}{ Las Vegas } \\
\hline & DCV \% & DCV\& ECO $\%$ & $\mathrm{DCV}$ & $\mathrm{DCV} \& \mathrm{ECO} \%$ \\
\hline$\overline{\mathrm{ECO}}$ & 0 & 2 & 0 & 8 \\
\hline DCV $75 \%$ Occ. & 9 & 11 & 11 & 15 \\
\hline \multirow[t]{3}{*}{ DCV $50 \%$ Occ. } & 19 & 21 & 19 & 23 \\
\hline & \multicolumn{2}{|c|}{ New York } & \multicolumn{2}{|c|}{ Denver } \\
\hline & DCV \% & DCV\& ECO $\%$ & $\mathrm{DCV}$ & $\mathrm{DCV} \& \mathrm{ECO} \%$ \\
\hline ECO & 0 & 7 & 0 & 11 \\
\hline DCV $75 \%$ Occ. & 12 & 16 & 15 & 19 \\
\hline DCV $50 \%$ Occ. & 21 & 24 & 22 & 26 \\
\hline
\end{tabular}

Table 2. Percentage of the annual cooling heating and total saving in energy use resulted from both DCV and economizer

\begin{tabular}{|c|c|c|c|c|}
\hline \multicolumn{2}{|c|}{$\%$ Occ. profile } & \multirow{2}{*}{$\begin{array}{l}\text { Cooling saving }(\%) \\
4\end{array}$} & \multirow{2}{*}{$\begin{array}{l}\text { Heating saving }(\%) \\
0\end{array}$} & \multirow{2}{*}{$\begin{array}{l}\text { Total saving }(\%) \\
2\end{array}$} \\
\hline Orlando & 100 & & & \\
\hline & 75 & 15 & 23 & 11 \\
\hline & 50 & 27 & 39 & 21 \\
\hline \multirow[t]{3}{*}{ LV } & 100 & 17 & 0 & 8 \\
\hline & 75 & 25 & 23 & 15 \\
\hline & 50 & 31 & 43 & 23 \\
\hline \multirow[t]{3}{*}{ NY City } & 100 & 13 & 0 & 7 \\
\hline & 75 & 22 & 11 & 16 \\
\hline & 50 & 30 & 22 & 24 \\
\hline \multirow[t]{3}{*}{ Denver } & 100 & 28 & 0 & 11 \\
\hline & 75 & 35 & 7 & 19 \\
\hline & 50 & 41 & 13 & 26 \\
\hline \multirow[t]{3}{*}{ Fargo } & 100 & 11 & 0 & 8 \\
\hline & 75 & 20 & 8 & 17 \\
\hline & 50 & 27 & 18 & 25 \\
\hline
\end{tabular}

\section{CONCLUSION}

The study discussed the applications of $\mathrm{CO}_{2}$-based demand-controlled ventilation DCV strategy integrated with the economizer for air source heat pumps in schools, investigates their impact on the annual energy consumption and determines the potential savings achieved in different USA locations. A 133,200 $\mathrm{ft}^{2}$ $\left(12375 \mathrm{~m}^{2}\right)$ middle school located near the city of Greensboro is used for this study. The school heating and cooling system includes a total of forty nine wall mounted air source heat pumps located in classrooms. In order to estimate the energy savings by implementing the DCV and the economizer, the school was first modeled using the whole building simulation energy software eQuest. The model is then calibrated using utility data of year 2009 and tested on other utility data covering four years. The calibrated and tested results showed that the model produces accurate estimations and the error is less than $5 \%$. The model error drops to less than $3 \%$ by adjusting to the major energy conservation measures that was applied to the school.

The exciting heat pump control supplies a fixed amount of fresh to the space based on design number of students and no economizer is applied. A substantial energy saving could be attained by implementing the economizer and ventilation control strategies. Two control methods (1) proportional control and (2) single set point control were proposed. Those control strategies require installing modulated damper, $\mathrm{CO}_{2}$ sensor and controller. The controller uses the $\mathrm{CO}_{2}$ signal to control and modulate the position of outdoor air damper and thereby provides the space with the proper amount of ventilation air. To investigate the energy benefits of using the $\mathrm{CO}_{2}$-based DCV integrated with economizer operation, the calibrated model were used. The simulated results show that by implementing the DCV and economizer, a significant energy saving can be achieved. The savings could vary from 19 to $26 \%$ depending on the 
locations and actual occupancy profile drifted from the design occupancy.

\section{REFERENCES}

ASHRAE, 2010. ASHRAE standard 62-2010, ventilation for acceptable indoor air quality. American Society of Heating, Refrigerating and Air-Conditioning Engineers, Inc., Atlanta.

Chao, C.Y.H. and J.S. Hu, 2004. Development of a dualmode demand control ventilation strategy for indoor air quality control and energy saving. Build. Environ., 39: 385-397. DOI: 10.1016/j.buildenv.2003.11.001

Lu, T., X. Lu and M. Viljanen, 2011. A novel and dynamic demand-controlled ventilation strategy for $\mathrm{CO}_{2}$ control and energy saving in buildings. Energy Build., 43: 2499-2508. DOI: 10.1016/j.enbuild.2011.06.005

Murphy, J., 2005. $\mathrm{CO}_{2}$-based demand-controlled ventilation with ashrae standard 62.1-2004, Trane Eng Newslett.

Nassif, N., 2012. A robust $\mathrm{CO}_{2}$-based demand-controlled ventilation control strategy for multi-zone HVAC systems. Energy Build., 45: 72-81. DOI: 10.1016/j.enbuild.2011.10.018

Nassif, N., S. Kajl and R. Sabourin, 2005. Ventilation control strategy using the supply $\mathrm{CO}_{2}$ concentration setpoint. Int. J. HVAC\&R Res., 11: 239-262. DOI: 10.1080/10789669.2005.10391136
Ng, M.O., M. Qu, P. Zheng, Z. Li and Y. Hang, 2011. $\mathrm{CO}_{2}$-based demand controlled ventilation under new ASHRAE Standard 62.1-2010: A case study for a gymnasium of an elementary school at West Lafayette, Indiana. Energy Build., 43: 3216-3225. DOI: 10.1016/j.enbuild.2011.08.021

Santamouris, M., A. Synnefa, M. Asssimakopoulos, I. Livada and K. Pavlou et al., 2008. Experimental investigation of the air flow and indoor carbon dioxide concentration in classrooms with intermittent natural ventilation. Energy Build., 40: 1833-1843. DOI: 10.1016/j.enbuild.2008.04.002

Shan, K., Y. Sun, S. Wang and C. Yan 2012. Development and In-situ validation of a multi-zone demand-controlled ventilation strategy using a limited number of sensors. Build. Environ., 57: 2837. DOI: 10.1016/j.buildenv.2012.03.015

Stanke, D., 2006. System operation: Dynamic reset options. ASHRAE J., 48: 18-32.

Taylor, S.T., 2006. $\mathrm{CO}_{2}$-based DCV using 62.1-2004. ASHRAE J., 48: 67-75.

Mysen, M., B.J. Wachenfeldt and P.G. Schild, 2007. Air flow rates and energy saving potential in schools with demand-controlled displacement ventilation. Energy Build., 39: 1073-1079. DOI:10.1016/j.enbuild.2006.10.018

Wang, S. and X. Xu, 2002. A robust control strategy of combined $\mathrm{dcv}$ and economizer control for airconditioning systems. Energy Convers. Manage., 18: 2569-2588. DOI: 10.1016/S0196-8904(01)00193-5 